\title{
ON THE IMPLICATIONS OF DEVELOPMENT FOR MORAL EDUCATION
}

\author{
Emmanuel Jerome Udokang* \\ http://dx.doi.org/10.4314/og.v12i 1.12
}

\begin{abstract}
This paper examines the concept of development and the implication it has for moral education. While using the word "development" in its general understanding as change from one stage to the other, it went beyond this to the psychological. It alludes that in terms of moral education, development is not just any behaviour change, but a change toward greater differentiation, integration, and adaptation. In other words, that development as a movement through a sequential progression represents movement from a less adequate psychological state to a more adequate psychological state. Using the method of analysis and description, it came to the conclusion that education for moral and general cognitive development must be judged by its contribution to a more general concept of egodevelopment.
\end{abstract}

\section{Development in Perspective}

The developmental-philosophic strategy in contrast with some other approaches can deal with two persistent problems: the ethical question of having a standard of non-relative or universal value and factual questions of prediction. The concept of development, as elaborated by cognitive-developmental theory, implies a standard of adequacy internal to, and governing, the developmental process itself (Udokang 2010). It is obvious that the notion of development must do more than merely define what comes later in time. This is so because it is not clear that what comes later must be better. For example, if anal interests mature later in time than oral interests, this in itself is no reason for claiming that the anal interests are better than the oral interests.

Cognitive-developmental theory, however, postulates a formal internal standard of adequacy which is not merely an order of events in time. In doing so it elaborates the ordinary-language meaning of the term “development". Webster's Dictionary tells us 
that to develop means "to make active, to move from the original position to one providing more opportunity for effective use, to cause to grow and differentiate along lines natural of its kind; to go through a process of natural growth, differentiation, or evolution by successive changes." This suggests an internal standard of adequacy governing development; it implies that development is not just any behaviour change, but a change toward greater differentiation, integration, and adaptation. Cognitive-developmental psychological theory postulates that movement through a sequential progression represents movement from a less adequate psychological state to a more adequate psychological state. The existence of this "internal standard of adequacy" is suggested by studies which show that the child prefers thinking at the next higher moral or logical stage to thinking at his own stage (or at lower stages) (Rest 86-109) and that he moves in that direction under normal conditions of stimulation.

The concept of development also implies that such an internal standard of adequacy is different from notions of adaptation based on culturally relative success or survival. As a case, we may take stages of morality. Being at the highest moral stage led Socrates and Martin Luther King to be put to death by members of their culture. Obviously, then, moral development cannot be justified as adaptive by standards of survival or of conformity to cultural standards. In terms of developmental psychological theory, however, Luther's morality was more adequate than the morality of most people who survive longer. Formally, Luther's morality was a more differentiated and integrated moral system than that of most people. It was more adequate because if all people adopted Luther's morality, it would resolve for everyone moral problems and conflicts unresolved by lower-stage moralities (Cochrane et al, 107).

As the example of Luther suggests, the formal standard of cognitive developmental psychological theory is not itself ultimate, but must be elaborated as a set of ethical and epistemological principles and justified by the method of philosophy and of ethics. The distinctive feature of the developmental-philosophic approach is that a philosophic conception of adequate principles is coordinated with a psychological theory of development and with the fact of development. 
In contrast to "value free" approaches, the approach suggested by Dewy and Piaget considers questions of value or adequacy at the very start. Piaget begins by establishing epistemological and logical criteria for deciding which thought structures are most adaptive and adequate for coping with complexity. Similarly, most works on ethical stages have taken a philosophic notion of adequate principles of justice (represented especially in the work of Kant and Rawls) as guide in defining the direction of development. Epistemological and ethical principles guide psychological inquiry from the start. Thus, this strategy attempts to avoid the naturalistic fallacy of directly deriving judgments of value from judgments about the facts of development, although it assumes that the two may be systematically related. It takes as a hypothesis for empirical confirmation or refutation that development is a movement toward greater epistemological or ethical adequacy as defined by philosophic principles of adequacy.

Our philosophical method differs from the approaches of philosophers of other persuasions in that the developmental method is partly empirical rather than purely analytic. It combines a prior conception of development with a prior notion of an ethical standard of adequacy: but these notions can be revised in the light of the facts, including the facts of development. If the facts of development do not indicate that individuals move toward philosophically desired principles of justice, then the initial philosophic definition of the direction of development is in error, and must be revised. The analytic and normative "ought" of the developmental philosophers must take into account the facts of development, but it is not simply a translation of these facts.

This method of "empirical" or "experimental" philosophy is especially central for an educational philosophy prescribing educational aims. But philosophical principles cannot be stated as ends of education until they can be stated psychologically. This means translating them into statements about a more adequate stage of development. Otherwise the rationally accepted principles of the philosopher will only be arbitrary concepts and doctrines for the child. Accordingly, to make a genuine statement of an educational end, the educational philosopher must coordinate notions of principles with understanding for the facts of development. 


\section{Development as the Aim of Education}

So far we have attempted to clarify and justify the basic claim that developmental criteria are the best ones for defining educationally important behaviour changes. We need now to clarify how the psychological study of development can concretely define educational goals. A common criticism is that the concept of development is too vague to clarify genuinely the choice of the curricular content and aims of education. A second, related criticism is that the concept of development, with its connotation of the "natural," is unsuited to determine actual educational policy.

These require to be examined. With regard to the issue of vagueness, if the concept of development is to aid in selecting educational aims and content, this assumes that only some behaviour changes out of many can be labeled developmental. We need to justify this assumption and to clarify the conditions for developmental change.

Our position here has been challenged by Bereiter, who claims that determining whether or not a behaviour change is developmental is a matter of theory, not an empirical issue (Bereiter 25-32). For example, Piagetian research shows that fundamental arithmetical reasoning (awareness of one-to-one correspondence of inclusion of a larger class in a sub-class, of addition and subtraction as inverse operations), usually develops naturally, without formal instruction or schooling, i.e., it constitutes development. Such reasoning can also be explicitly taught, however, following various non-developmental learning theories. Accordingly, says Bereiter, to call fundamental arithmetical reasoning developmental does not define it as a developmental educational objective distinct from nondevelopmental objectives like rote knowledge of the multiplication tables.

In answer, the cognitive-developmental position claims that developmental behaviour change is irreversible, general over a field of responses, sequential, and hierarchical (Kohlberg 40-48). When a set of behaviour changes meet all these criteria, changes are termed stages or structural reorganizations. A specific area of behavioural change like fundamental arithmetical reasoning may or may not meet these criteria. Engelmann claims to have artificially taught 
children the "naturally developing" operation of conservation, but Kamii (1971) found that the children so taught met Engelmann's criteria of conservation without meeting the criteria of development, e.g., the response could be later forgotten or unlearned, it was not generalized, and so forth.

When a set of responses taught artificially do not meet the criteria of natural development this is not because educational intervention is generally incompatible with developmental change. It is because the particular intervention is found to mimic development rather than to stimulate it. The issue of whether an educational change warrants the honorific label "development" is a question for empirical examination, not simply a matter of theory.

We have claimed that development can occur either naturally or as the result of a planned educational program. As was discussed earlier, development depends on experience. It is true, however, that the way in which experience stimulates development (through discrepancy and match between experienced events and information-processing structures) is not the way experience is programmed in many forms of instruction and educational intervention. It is also true that the kinds of experience leading to development must be viewed in terms of a stimulation which is general rather than highly specific in its content or meaning.

Because the experiences necessary for structural development are believed to be universal, it is possible for the child to develop the behaviour naturally, without planned instruction. But the fact that only about half of the adult population fully reaches Piaget's stage of formal operational reasoning and only five percent $(5 \%)$ reach the highest moral stage demonstrates that natural or universal forms of development are not the inevitable but depend on experience (Kuhn et al 1971).

If this argument is accepted, it not only answers the charge that development is a vague concept but helps answer the charge that there are kinds of development (such as growth in skill at burglary) which are not valuable. Such questionable types of "development" do not constitute development in the sense of a universal sequence or in the sense of growth of some general aspect of personality. As stated by Dewey: 
That a man may grow in efficiency as a burglar ... cannot be doubted. But from the standpoint of growth as education and education as growth the question is whether such growth promotes or retards growth in general (75).

While a coherent argument has been made for why universal developmental sequences define something of educational value, we need to consider why such sequences comprise the ultimate criteria of educational value. We also need to consider how they relate to competing educational values. How does universal structural development as an educational aim relate to ordinary definitions of information and skills central to the educational curriculum? It seems obvious that many changes or forms of learning are of values which are not universals in development. As an example, while many unschooled persons have learned to read, the capacity and motivation to read does not define a developmental universal; nonetheless, it seems to us a basic educational objective. We cannot dispose of "growth in reading" as an educational objective as we can "growth in burglary," simply because it is not a universal in development. But we argue that the ultimate importance of learning to read can only be understood in the context of more universal forms of development. Increased capacity to read is not itself a development, although it is an attainment reflecting various aspects of development. The value or importance of reading lies in its potential contribution to further cognitive, social, and aesthetic development.

A developmental definition of educational objectives must not only cope with competing objectives usually defined nondevelopmentally, but with the fact that the universal aspects of development are multiple. Here, as in the case of evaluating nondevelopmental objectives, the progressive educator must consider the relation of a particular development to development in general. As an example, Kamii has defined a program of preschool intervention related to each of the chapter headings of Piaget's books: space, time, causality, number, classification, and so on (1971). Kamii's intention in making use of all the areas of cognitive 
development discussed by Piaget is not to imply that each constitutes a separate, intrinsic educational objective. Rather, her interest is to make use of all aspects of the child's experience relevant to general Piagetian cognitive development. Such a concept of generalized cognitive-stage development is meaningful because Kohlberg and DeVries and others have shown that there is a general Piagetian cognitive-level factor distinct from psychometric general intelligence (1971).

In contrast to the psychometric concept of intelligence, the developmental level concept of intelligence does provide a standard or a set of aims for pre-school education. It does not assume a concept of fixed capacity or "intelligence quotient" constant over development. In this sense, developmental level is more like "achievement" than like "capacity," but developmental level tests differ from achievement tests in several ways. While the developmental level concept does not distinguish between achievement and capacity, it distinguishes between cognitive achievement (performance) and cognitive process (or competence). Developmental tests measure level of thought process, not the difficulty or correctness of thought product. They measure not cognitive performance but cognitive competence, the basic possession of a core concept, not the speed and agility with which the concept is expressed or used under rigid test conditions.

Psychometric and developmental level concepts of intelligence are quite different. In practice, however, the two kinds of measures are highly correlated with one another, explaining why clear theoretical and operational distinctions between the two concepts of intelligence have not been made until recently. Factoranalytic findings now can provide an empirical basis for this distinction (Kamii 1971). While psychometric measures of general intelligence and of "primary mental abilities" at mental age six correlate with Piagetian measures of cognitive level, there is also a common factor to all developmental level tests. This factor is independent of general intelligence or of any special psychometric ability. In other words, it is possible to distinguish between psychometric capacity and developmental level concepts or measures of intelligence. Given the empirical distinction, cognitive stage measures provide a rational standard for educational 
intervention where psychometric intelligence tests do not. This is true for the following reasons:

(i)

(ii)

(iii)

(iv)

The core structure defined by stage tests is in theory and experiment more amenable to educational intervention - Piagetian theory is a theory of stage movement occurring through experience of structural equilibrium.

Piagetian performance predicts later development independent of a fixed biological rate or capacity factor, as demonstrated by evidence for longitudinal stability or prediction independent of I.Q. Because Paiget items define invariant sequences, development to one stage facilitates development to the next.

Piagetian test content has cognitive value in its own right. If a child is able to think causally instead of magically about phenomena, for instance, his ability has a cognitive value apart from arbitrary cultural demands - it is not a mere indicator of brightness, like knowing the word "airplane" or "confidence." This is reflected in the fact that Piaget test scores are qualitative; they are not arbitrary point on a curve. The capacity to engage in concrete logical reasoning is a definite attainment; being at mental age six is not. We can ask that all children have high I.Q.'s.

This cognitive value is culturally universal, the sequence of development occurs in every culture and subculture.

The existence of a great level factor in cognitive development allows us to put particular universal sequences of cognitive development into perspective as educational aims. The worth of a development in any particular cognitive sequence is 
determined by its contribution to the whole of cognitive development.

We must now consider the relation of developmental aims of education to the notion of developmental acceleration as an educational objective. We indicated that a concept of stages as "natural" does not mean that they are inevitable; many individuals fail to attain the higher stages of logical and moral reasoning. Accordingly, the aim of the developmental educator is not the acceleration of development but the eventual adult attainment of the highest stage. In this sense, the developmentalist is not interested in stage-acceleration, but in avoiding stage retardation. Moral development research reviewed elsewhere suggests that there is what approaches an optimal period for movement from one stage to the next (Kohlberg 1976, 31-53). When a child has just attained a given stage, he is unlikely to respond to stimulation toward movement to the next stage. In addition, after a long period of use of a given stage of thought, a child tends to "stabilize" at that stage and develops screening mechanisms for contradictory stimulation. Accordingly, it has been found that both very young and very old children at a given stage (compared to the age-norm for that stage) are less responsive or less able to assimilate stimulation at the next higher stage than children at the age-norm for that age. The notion of an "open period" is not age-specific, it is individual. A child late in reaching Stage 2 may be "open" to Stage 3 at an age beyond that of another child who reached Stage 2 earlier. Nevertheless, gross age-periods may be defined which are "open periods" for movement from one stage to the next. Avoidance of retardation as an educational aim means presenting stimulation in these periods where the possibility for development is still open.

We need to consider a related distinction between acceleration and decalage as an aim of education. Piaget distinguishes between the appearance of a stage and its "horizontal decalage," its spread pf generalization across the range of basic physical and social actions, concepts, and objects to which the stage potentially applies. As a simple example, concrete logic or conservation is first noted in the concept of mass and only later in weight and volume. Accordingly, acceleration of the stage of concrete operations $\mathrm{s}$ one educational enterprise and the 
encouragement of decalage of concrete reasoning to a new concept or phenomenon is another. It is the latter which is most relevant to education. Education is concerned not so much with age of onset of a child's capacity for concrete logical thought, but with the possession of a logical mind - the degree to which he has organized his experience or his world in a logical fashion.

It is likely that the occurrence of such horizontal decalage, rather than age of first appearance of concrete operations, predicts to later formal operational thought. Formal reasoning develops because concrete reasoning represents a poor, though partially successful, strategy for solving many problems. The child, who has never explored the limits of concrete reasoning and lives in a world determined by arbitrary unexplained events and forces, will see the limits of the partial solutions of concrete logic as set by intangible forces, rather than looking for a more adequate logic to deal with unexplained problems.

We have so far discussed development only as general cognitive development. According to cognitive-developmental theory there is always a cognitive component to development, even in social, moral and aesthetic areas. Development, however, is broader than cognitive-logical development. One central area is moral development, as defined by invariant stages of moral reasoning (Kohlberg 1971). On the one hand, these stages have a cognitive component; attainment of a given Piaget cognitive stage is a necessary, though not sufficient, condition for the parallel moral stage. On the other hand, moral reasoning stages relate to action; principled moral reasoning has been found to be a precondition for principles moral actions (Kohlberg 1976, 31-53). The stimulation of moral development through the stages represents a rational and ethical focus of education related to, but broadening, an educational focus upon cognitive development as such. ${ }^{13}$ Programs effective in stimulating moral development have been successfully demonstrated (Blatt 1975, 129-161).

While developmental moral education widens the focus of cognitive-developmental education beyond the purely cognitive, there is a still broader unity, called ego-development, of which both cognitive and moral development are part (Loevinger, 1970). Particularly in the earlier childhood years, it is difficult to 
distinguish moral development from ego-development. Cognitive development, in the Piagetian sense, is also related to ego development, since both concern the child's core beliefs about the physical and social world. Much recent research demonstrates that the development of the ego as attitudes and beliefs about the self, involves step-by-step parallel development of attitudes and beliefs about the physical and social world. Further, it indicates definite stages of ego-development, defined by Loevinger et al. (1970), van den Daele (1970, 296-304) and others, which imply step-by-step parallels to Piaget's cognitive stages, although they include moral social emotional content. In general, attainment of a Piagetian cognitive stage is a necessary but not sufficient condition for attainment of the parallel ego stage. All children at a given ego stage must have attained the parallel cognitive stage, but not all children at a cognitive age will have organized their self-concept and social experience at the corresponding ego stage. Thus, a general concept of ego-development as a universal sequential phenomenon is becoming an empirically meaningful guide to defining broad educational objectives. Furthermore, experimental educational programs to stimulate ego-development have been piloted with some definite success at both the preschool and the high school levels (Daele 1970, 911-924).

Thus education for general cognitive development, and perhaps even education for moral development, must be judged by its contribution to a more general concept of ego-development. In saying this, we must remember that "Ego -development" is the psychologist's term for a sequence which also must have a philosophic rationale. One pole of ego-development is selfawareness; the parallel pole is awareness of the world. Increasing awareness is not only "cognitive," it is moral, aesthetic, and metaphysical; it is the awareness of new meanings in life.

Finally, we need to note that in the realm of egodevelopment, a focus upon "horizontal decalage" rather than accelerated is especially salient. The distinction reflects in a more precise, and viable fashion the concern of maturational or romantic stage theorists for an educational focus upon "healthy" passage through stages, rather than their acceleration. In maturational theories of personality stages, age leads to a new stage regardless of 
experience and organizations at previous stages. As a result, education and experience become valuable not for movement to a new stage, but for healthy or successful integration of the concerns of a stage. Onset of the next stage occurs regardless of experience; it is only integration of the stages which is contingent on experience and which should be the focus for education. Without accepting this contention, cognitive-developmental theory would agree that premature development to a higher ego stage without a corresponding decalage throughout the child's world and life presents problems. In psychoanalytic maturational terms, the dangers of uneven or premature ego development are expressed as defects in ego-strength with consequent vulnerability to regression. In cognitive developmental terms, inadequate "horizontal decalage" represents a somewhat similar phenomenon. While the relation of "ego strength" to logical and moral decalage is not well understood, there are many reasons to believe they are related. A child who continues to think in magical or egocentric terms in some areas of cognition and morality is likely to be vulnerable to something like "regression" under stress later in life.

\section{Conclusion}

Let us conclude this paper by saying that if a broad concept of development, conceived in stage-sequential terms, is still vague as a definer of educational ends, it is not due to the inherent narrowness or vagueness of the concept. Rather, it is due to the fact that researchers have only recently begun the kind of longitudinal and educational research needed to make the concept precise and useable. When Dewey advocated education as development most American educational psychologists turned to industrial psychology or to the mental health bag of virtues. If the results of the cognitivedevelopmental research of the last decades are still limited, they indicate real promise for finally translating Dewey's vision into a precise reality.

*Emmanuel Jerome Udokang, Ph.D, Department of Philosophy and Religions, University of Benin, Benin, Edo State - Nigeria. 


\section{References}

Bereiter, C. "Educational Implications of Kohlberg's CognitiveDevelopmental Views" in Interchange, 1 (2), 1970, 25-32.

Blatt, M. and Kohlberg, L. "The Effects of Classroom Moral Discussion Upon Children's Level of Moral Judgment," Journal of Moral Education, 4 (2), 1975, 129-161.

Cochrane, B. et al (Eds). The Domain of Moral Education. New York: Paulist Press, 2002

Dewey, J. Experience and Education. New York: Collier, 1998.

Kamii, C. "Evaluating Pupil Learning in Pre-School Education: Socio-emotional Perceptual Motor, and Cognitive Objectives," in Formative and Summative Evaluation of Student Learning. B.S. Bloom, J. T. Hastings and G. Madaus (Eds.). New York: McGraw-Hill, 1971.

Kohlberg, L. et al. "Relations between Piaget and Psychometric Assessments of Intelligence," in The National Curriculum. C. Lavatelli (Ed.). Urbana, Illinois: Eric, 1971.

Kohlberg, L. "Moral Stages and Moralization: The CognitiveDevelopmental Approach" in Moral Development and Behaviour. Thomas Lickona (Ed.). New York: Holt, Rinehart and Winston, 2013, 31-53.

Kohlberg, L. and E. Turiel, "Moral Development and Moral Education" in Psychology and Educational Practice. Lesser, G. (ed.). Chicago: Scott Foresman, 1971.

Kuhn, D. et al. The Development of Formal Operations in Logical and Moral Judgment.New York: ColumbiaUniversity, 1997.

Loevinger, J. et al. Measuring Ego Development.San Francisco: Jossey Bass 1990.

Rest, J. "Patterns of Preference and Comprehension in Moral Judgment, ” in Journal of Personality 41, 1973, 86-109.

Udokang, E. J. \& Odigie, J. N. Development and Moral Education, Swems: Journal of Religion and Philosophy, Department of Religion and Philosophy, Benue State University, Markurdi. Vol 4, No 1, 2014, 39 - 51.

Van den Daele, L. "Pre-School Intervention with Social Learning" in Journal of Negro Education, 39 (Fall) 1970. 296-304. 